\title{
The Effect of Amiloride on Proteinuria in Patients with Proteinuric Kidney Disease
}

\author{
Wen Shen Mohammed Alshehri Sameer Desale Christopher Wilcox \\ Division of Nephrology and Hypertension, Department of Medicine, MedStar Georgetown University Hospital, \\ Washington, DC, USA
}

\section{Keywords}

Amiloride $\cdot$ Proteinuria $\cdot$ Chronic kidney disease $\cdot$ Clinical trial

\begin{abstract}
Introduction: Proteinuric kidney diseases share an aggressive clinical course of developing end-stage renal disease. However, the treatment is limited. Amiloride, an epithelial sodium channel (ENaC) inhibitor, was reported to reduce proteinuria in animal studies and case reports independent of ENaC inhibition. We hypothesized that amiloride not triamterene (an analog of amiloride) would reduce proteinuria in the patients with proteinuric kidney disease. Methods: Patients with proteinuria $>1.0 \mathrm{~g} /$ day and estimated glomerular filtration rate $(e G F R)>30 \mathrm{~mL} / \mathrm{min} / 1.73 \mathrm{~m}^{2}$ on a maximum tolerable dose of angiotensin-converting enzyme inhibitors or angiotensin II receptor blockers were randomized to receive amiloride $5 \mathrm{mg}$ twice daily or triamterene $50 \mathrm{mg}$ twice daily for 8 weeks, followed by 4 weeks of washout, and then crossed over to the other drug for 8 weeks. The primary outcome was 24-h urine protein reduction. Secondary outcomes were changes in body weight, blood pressure (BP), serum potassium, and eGFR. Data were analyzed by analysis
\end{abstract}

karger@karger.com

(c) 2021 S. Karger AG, Basel

www.karger.com/ajn

Karger of variance. Results: A total of 12 patients completed the study. Amiloride reduced $24-\mathrm{h}$ urine protein by $38.7 \%(p=$ $0.002)$ and decreased systolic BP by $12.3 \mathrm{~mm} \mathrm{Hg}(p=0.04)$. Interestingly, triamterene reduced $24 \mathrm{~h}$ urine protein as well, by $32.8 \%(p=0.02)$. Triamterene lowered eGFR by $9.0 \mathrm{~mL} /$ $\mathrm{min} / 1.73 \mathrm{~m}^{2}(p=0.007)$, but it was reversible. The average weight change was insignificant in both groups $(p=0.40$ and 0.34 respectively). Three patients withdrew the study due to hyperkalemia. Conclusions: Both amiloride and triamterene significantly reduced proteinuria in patients with proteinuric kidney disease. The anti-proteinuric effect was additive to renin-angiotensin-aldosterone system (RAAS) blockade, given all patients were on RAAS blockade. Hyperkalemia was a safety concern. Larger trials might be needed to examine the antiproteinuric effects of $\mathrm{ENaC}$ inhibitors.

(C) 2021 S. Karger AG, Basel

\section{Introduction}

Proteinuria is a major determinant of progression of chronic kidney disease (CKD), which is associated with more rapid worsening of renal function and earlier initiation of renal replacement therapy independent of esti- 
mated glomerular filtration rate (eGFR) [1]. The rate of progression to end-stage renal disease among diabetic individuals with macroalbuminuria (urine albumin to creatinine ratio [UACR] $>300 \mathrm{mg} / \mathrm{g}$ ) was 9.3 times greater than that of those with normoalbuminuria (UACR $<30$ $\mathrm{mg} / \mathrm{g}$ ), controlled for age, gender, and duration of diabetes [2]. Proteinuria stimulates tubular chemokine expression and activates complement pathway which result in inflammatory response and fibrosis in the interstitium that contributes to progression of CKD [3]. Randomized controlled studies in patients with proteinuric kidney diseases have reported that a sustained reduction in proteinuria prevents or slows long-term GFR decline irrespective of the treatment administrated or the primary cause of CKD $[4,5]$.

Since proteinuria is one of the most important modifiable risk factors to slow the progression of proteinuric kidney diseases, a reduction of proteinuria has been recognized as an independent treatment target for renoprotective intervention. Inhibition of renin-angiotensin-aldosterone system (RAAS) to reduce proteinuria has been the mainstay treatment for decades. Recently, emerging data have shown the anti-proteinuric effects of selective inhibition of sodium-glucose cotransporter 2 and selective inhibition of mineralocorticoid receptor in diabetic kidney disease $[6,7]$. But the search for the therapy of proteinuria reduction and renoprotection is still ongoing. Amiloride - an epithelial sodium channel (ENaC) inhibitor - traditionally is used to reduce blood pressure (BP) and edema, but has been reported to reduce proteinuria in animal studies. In salt-drinking stroke-prone spontaneously hypertensive rats, amiloride delayed the onset of proteinuria [8]. Amiloride, but not triamterene - another $\mathrm{ENaC}$ inhibitor - attenuated proteinuria and glomerulosclerosis in the 5/6 nephrectomized proteinuric rat model and the lipopolysaccharide mouse model. The antiproteinuric effect has been related to its inhibition of podocyte urokinase plasminogen activator receptor (uPAR) expression and $\beta 3$ integrin activity, independent of $\mathrm{ENaC}$ inhibition [9]. However, the role of UPAR in podocyte injury and proteinuria is controversial [10]. The effect of amiloride in reducing proteinuria in human kidney disease has been reported sporadically in several case reports, including IgA nephropathy, Fabry disease, and Alport disease [11-13]. Interestingly, a human study that was designed to use amiloride to treat edema and hypertension in diabetic patients demonstrated a significant reduction of albuminuria in patients with diabetic nephropathy [14]. Another human study to investigate if amiloride increased natriuresis and lowered BP showed
$10-15 \%$ reduction of albuminuria in the patients with diabetic kidney disease [15].

To our knowledge, no human study has been specifically designed to test the hypothesis if amiloride has significant antiproteinuric effect in patients with proteinuric kidney disease. We designed this randomized, crossover study to examine the effect of amiloride on proteinuria reduction as the primary outcome. Since another $\mathrm{ENaC}$ inhibitor triamterene - an analog of amiloride - did not reduce proteinuria and hinder glomerulosclerosis in the animal study [9], we intended to use triamterene as a control drug in this study.

\section{Methods}

\section{Patient Selection}

Patients with any type of proteinuric kidney diseases and those meeting the inclusion criteria were eligible for the study. The inclusion criteria were as follows: age $\geq 18$ years old, 24 -h urine protein $>1.0 \mathrm{~g}$, eGFR $\geq 30 \mathrm{~mL} / \mathrm{min} / 1.73 \mathrm{~m}^{2}$, serum potassium $(\mathrm{Sk}) \leq 4.8$ $\mathrm{mmol} / \mathrm{L}$ if $\mathrm{eGFR} \geq 45 \mathrm{~mL} / \mathrm{min} / 1.73 \mathrm{~m}^{2}$ or $\mathrm{Sk} \leq 4.5 \mathrm{mmol} / \mathrm{L}$ if $\mathrm{eGFR}$ between 30 and $44 \mathrm{~mL} / \mathrm{min} / 1.73 \mathrm{~m}^{2}$, or on highest tolerable dose of ACE inhibitor or ARB for at least 8 weeks. Exclusion criteria included the following: clinical evidences of any inflammatory diseases, including lupus, rheumatoid arthritis, inflammatory bowel disease or HIV infection, etc.; $\mathrm{eGFR}<30 \mathrm{~mL} / \mathrm{min} / 1.73 \mathrm{~m}^{2}$; requirement for treatment with mineralocorticoid receptor antagonist (spironolactone and eplerenone); status post-kidney transplant; received glucocorticoid steroids or immunosuppressant in the past 6 months; Sk $>4.8 \mathrm{mmol} / \mathrm{L}$; TCO $2<17 \mathrm{mmol} / \mathrm{L} ; \mathrm{Hb}<10 \mathrm{~g} / \mathrm{dL}$; contraindication or allergy to ACE inhibitors, ARBs, loop diuretics or potassium sparing diuretics; abnormal liver function tests; or unable to comprehend and comply with the informed consent.

\section{Study Design and Outcomes}

The study includes 3 phases. All patients received an ACE inhibitor or an ARB at the highest tolerated dose for at least 8 weeks prior to and throughout the study. Two patients were on thiazide diuretics prior to the study, but no patient was on loop diuretics. Both continued thiazide diuretics during the trial. The patients were randomly allocated in a 1:1 ratio to start with either amiloride or triamterene (Fig. 1).

Phase 1 (week 1-8): patients were randomized to receive either amiloride $5 \mathrm{mg}$ twice daily or triamterene $50 \mathrm{mg}$ twice daily for 8 weeks. Phase 2 (week 9-12): patients discontinued amiloride or triamterene for a washout for 4 weeks to mitigate the carryover effects from the medication with continuation of ACE inhibitor or ARB. Phase 3 (week 13-20): patients crossed over to triamterene or amiloride for 8 weeks (Fig. 2). BP was measured at each visit using an Omron Digital Blood Pressure Monitor (Omron Healthcare, Lake Forest, IL, USA). BP measurement was taken by a nurse at the Clinical Research Unit of GHUCCTS after the patient had rested for at least $5 \mathrm{~min}$ in a quiet room. Body weight was monitored during each visit. Twenty-four-hour urine protein and creatinine excretion; spot urine protein, albumin, and creatinine; serum electrolytes, creatinine, and bicarbonate were measured at 


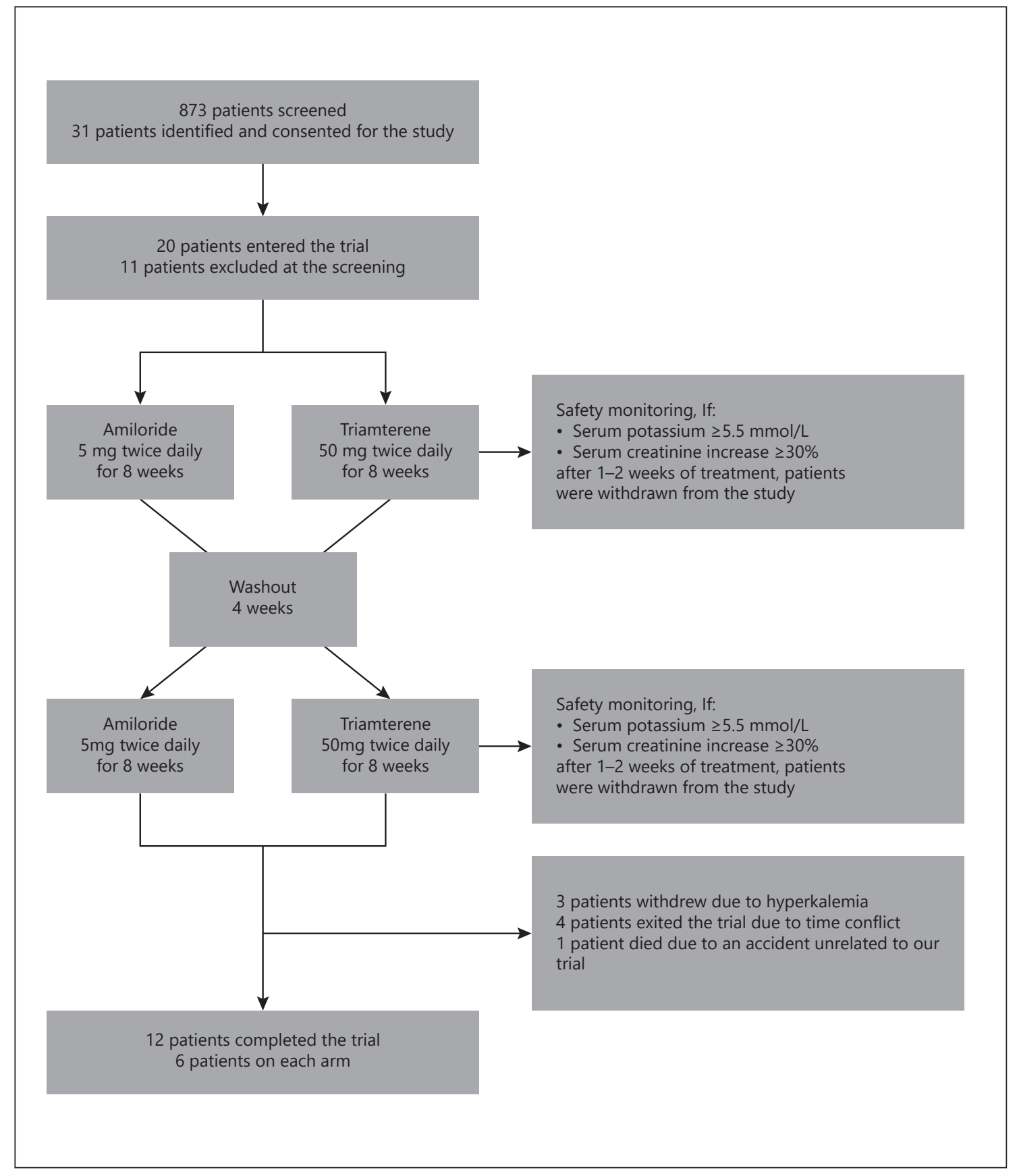

Fig. 1. Study flowchart of patient selection, randomization, and safety monitoring. Sk, serum potassium.

MedStar Georgetown University Hospital chemistry laboratory. The samples were collected and measured on the day of starting the study (considered as baseline week 0$), 1$ week after starting the phase 1 and 3 (week 1 and 13), and the last day of each phase (week 8 , week 12 and week 20). To ensure the accuracy of 24-h urine collection, urine creatinine values $<15 \mathrm{mg} / \mathrm{kg} /$ day for female, $<20 \mathrm{mg} /$ $\mathrm{kg} /$ day for male; or $>20 \mathrm{mg} / \mathrm{kg} /$ day for female, $>25 \mathrm{mg} / \mathrm{kg} /$ day for male were considered as under or over collection, and data were discarded.
Patient's adherence with the study medications was monitored by pill counts, self-report, a phone call from the study coordinator 4 weeks after starting phase 1 and 3 , and at the last visit of each study phase. The primary outcome was change in 24 -h urine protein excretion, urine protein/creatinine ratio, and urine albumin/ creatinine ratio. The secondary outcomes were changes in BP, body weight, Sk, and eGFR. 


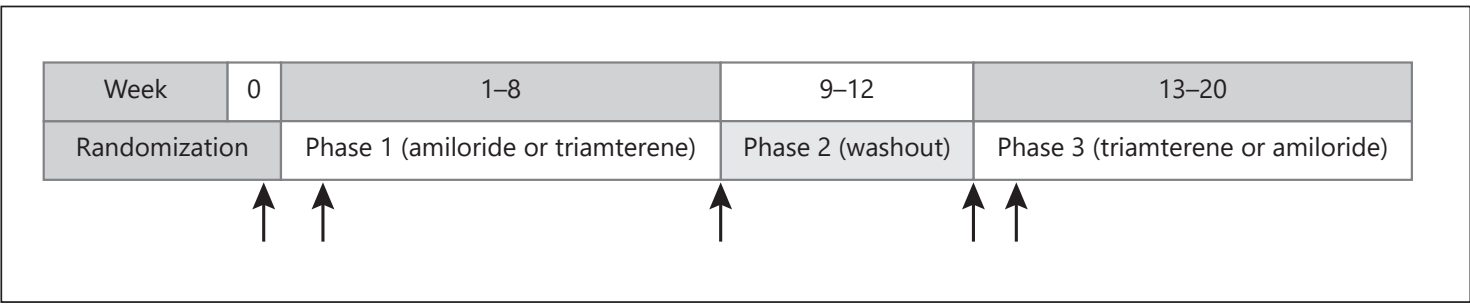

Fig. 2. The changes of 24 -h urine protein excretion in individual patients during the study.

Table 1. Baseline characteristics of the patients that completed the study

\begin{tabular}{|c|c|c|c|}
\hline & $\begin{array}{l}\text { Total patients } \\
(N=12)\end{array}$ & $\begin{array}{l}\text { Amiloride-triamterene } \\
(N=6)\end{array}$ & $\begin{array}{l}\text { Triamterene-amiloride } \\
(N=6)\end{array}$ \\
\hline Age, year & $54.7 \pm 12.1$ & $50.3 \pm 13.4$ & $59.0 \pm 11.4$ \\
\hline Gender, male \% & 75.0 & 50.0 & 100 \\
\hline \multicolumn{4}{|l|}{ Race, $\%$} \\
\hline Caucasian & 16.7 & 16.7 & 16.7 \\
\hline Asian & 33.3 & 50.0 & 16.7 \\
\hline African American & 50.0 & 33.3 & 67.7 \\
\hline Weight, kg & $79.6 \pm 18.1$ & $75.7 \pm 19.0$ & $84.4 \pm 17.8$ \\
\hline Systolic BP, mm Hg & $136.7 \pm 18.4$ & $139.8 \pm 22.8$ & $133.5 \pm 14.2$ \\
\hline Diastolic BP, mm Hg & $74.9 \pm 8.7$ & $74.5 \pm 5.0$ & $75.3 \pm 11.9$ \\
\hline Serum creatinine, $\mathrm{mg} / \mathrm{dL}$ & $1.11 \pm 0.3$ & $1.01 \pm 0.3$ & $1.2 \pm 0.4$ \\
\hline eGFR (CKD-EPI), mL/min & $80.6 \pm 23.1$ & $84.0 \pm 20.3$ & $77.2 \pm 27.2$ \\
\hline eGFR $\geq 60 \mathrm{~mL} / \mathrm{min}$, patient $(n)$ & 10 & 5 & 5 \\
\hline eGFR $45-59 \mathrm{~mL} / \mathrm{min}$, patient $(n)$ & 2 & 1 & 1 \\
\hline eGFR 30-44 mL/min, patient $(n)$ & 0 & 0 & 0 \\
\hline Serum potassium, $\mathrm{mEq} / \mathrm{L}$ & $4.0 \pm 0.3$ & $4.1 \pm 0.5$ & $4.0 \pm 0.3$ \\
\hline Serum albumin, $\mathrm{g} / \mathrm{dL}$ & $3.5 \pm 0.8$ & $3.1 \pm 1.0$ & $3.9 \pm 0.3$ \\
\hline Serum hemoglobin, g/dL & $12.4 \pm 2.2$ & $11.8 \pm 1.2$ & $12.9 \pm 2.8$ \\
\hline 24-h urine protein, $g$ & $2.90 \pm 1.67$ & $3.19 \pm 1.07$ & $2.76 \pm 2.07$ \\
\hline Urine protein/creatinine, $\mathrm{g} / \mathrm{g}$ & $2.76 \pm 1.75$ & $3.26 \pm 2.01$ & $2.26 \pm 1.45$ \\
\hline Urine albumin/creatinine, $\mathrm{g} / \mathrm{g}$ & $2.25 \pm 1.42$ & $2.68 \pm 1.65$ & $1.81 \pm 1.13$ \\
\hline 24-h urine sodium, mmol & $136.1 \pm 61.3$ & $136.9 \pm 41.3$ & $164.2 \pm 62.9$ \\
\hline \multicolumn{4}{|l|}{ Diagnosis } \\
\hline Diabetic nephropathy & 3 & 1 & 2 \\
\hline Hypertensive nephrosclerosis & 2 & 0 & 2 \\
\hline Membranous nephropathy & 3 & 2 & 1 \\
\hline IgA nephropathy & 2 & 2 & 0 \\
\hline Membranoproliferative GN & 1 & 1 & 0 \\
\hline Unspecified GN & 1 & 0 & 1 \\
\hline
\end{tabular}

Sk, serum potassium; eGFR, estimated glomerular filtration rate; BP, blood pressure. Baseline data were collected after patients were on 8 weeks of highest tolerable dose of RAAS blockade and right before entering the study.

\section{Patient Safety}

To ensure patient safety, Sk, creatinine, and bicarbonate were carefully monitored right before study onset, and 1 week after starting the trial drug during phases 1 and 3. For patients with Sk $\leq 5.0 \mathrm{mmol} / \mathrm{L} 1$ week after starting the trial drug, the trial drug was continued at the same dose until the end of phase 1 or 3. If the Sk was $\geq 5.5 \mathrm{mmol} / \mathrm{L} 1$ week after the trial drug was started, the patient had to exit the study, and an adverse event was recorded. If the Sk was $5.1-5.4 \mathrm{mmol} / \mathrm{L}$, it was repeated in 1 week, and if the repeated Sk was $\geq 5.5 \mathrm{mmol} / \mathrm{L}$, the patient exited the study, and an adverse event was recorded. If the repeated Sk remained in 5.1-5.4 $\mathrm{mmol} / \mathrm{L}$ or $\leq 5.0 \mathrm{mmol} / \mathrm{L}$, the patient continued the treatment phase. In addition, if serum creatinine increased $>30 \%$ during the study period or if patient required a change in his/her dose of ACE inhibitor or $A R B$, the patient was withdrawn from the study. eGFR was calculated by CKD-EPI creatinine equation. 
Fig. 3. The comparison of 24 -h urine protein excretion between amiloride and triamterene before and after the treatment. There was no significant difference in the urine protein excretion between 2 group either pre- $(p=0.85)$ or posttreatment $(p=$ $0.45)$.

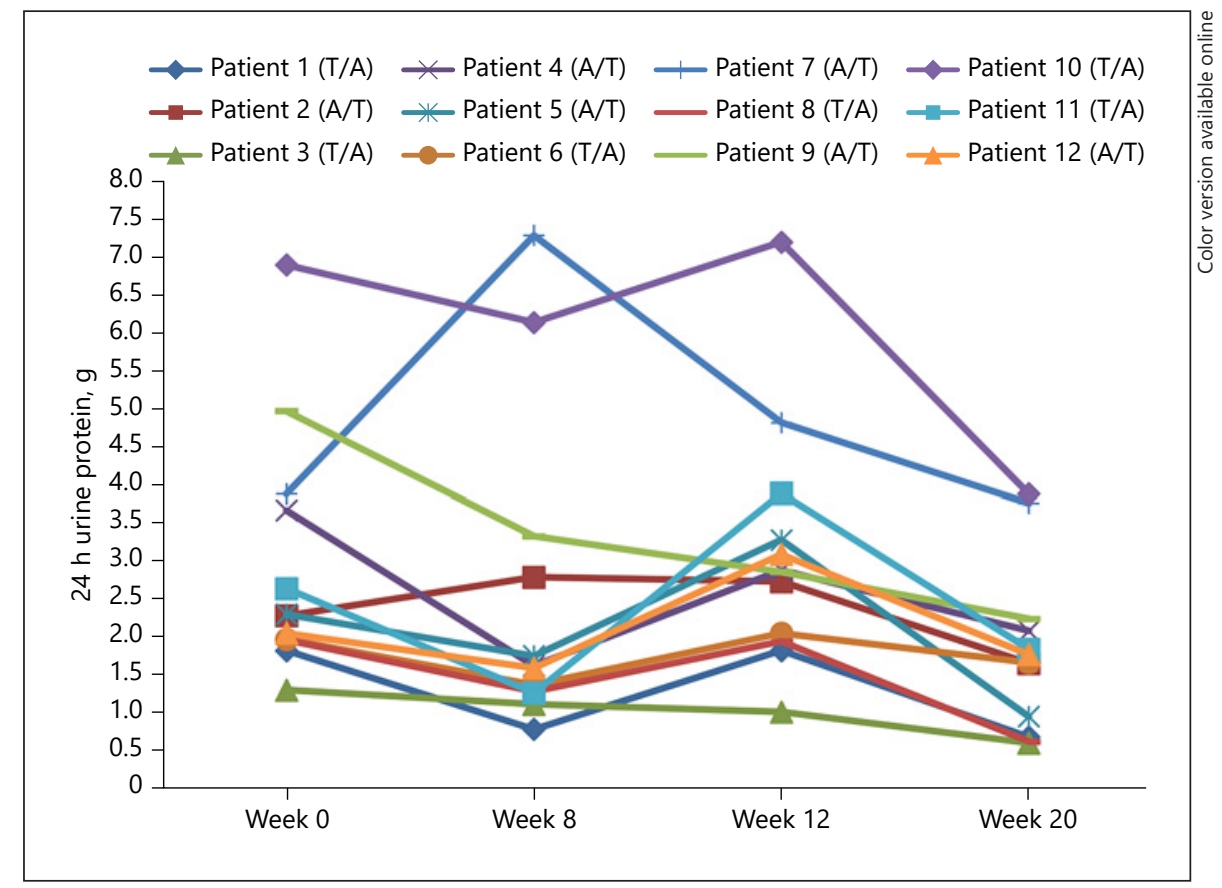

Statistical Analysis

This study was designed as a crossover pilot clinical trial where each patient was his/her own control. Accordingly, we used repeated measures 2-way analysis of variance to analyze the differences between the treatments, difference between pre to post, and difference in difference. We recruited 20 patients since the sample size could provide $>80 \%$ power to detect a mean decrease in proteinuria by $20 \%$ in the treatment group compared to the control with a $\mathrm{SD}=10 \%$ using 2 -sided paired $t$ test at alpha level of 0.05 .

\section{Results}

Of 873 patients screened in our renal clinic, 31 patients were identified and gave the consent for enrollment. Eleven of them failed to meet the inclusion criteria and were excluded, including 6 patients with proteinuria $<1 \mathrm{~g} /$ day, 2 patients with eGFR $<30 \mathrm{~mL} / \mathrm{min} / 1.73 \mathrm{~m}^{2}, 2$ patients with elevated $\mathrm{Sk}>4.8 \mathrm{mmol} / \mathrm{L}$, and 1 patient on azathioprine within 6 months prior to the study. Twenty patients met the inclusion criteria and were enrolled in the study. Eventually 12 patients completed the study (Fig. 1). 8 patients withdrew in the middle of the study due to hyperkalemia (3 patients), time conflict (4 patients), and death due to an accident unrelated to our trial (1 patient).

The baseline characteristics are shown in Table 1. The mean age for was $54.7 \pm 12.1$ years old, $75 \%$ were males, mean eGFR was $80.6 \pm 23.1 \mathrm{~mL} / \mathrm{min} / 1.73 \mathrm{~m}^{2}$, and mean Sk was $4.0 \pm 0.3 \mathrm{mmol} / \mathrm{L}$. Among the 12 patients, 3 pa- tients had diabetic nephropathy, 2 patients had hypertensive nephropathy, 3 patients had membranous nephropathy, 2 patients had IgA nephropathy, 1 patient had membranoproliferative nephropathy, and 1 patient had unspecified glomerulonephritis. Diabetic nephropathy, hypertensive nephropathy, and unspecified glomerulonephritis were diagnosed clinically. Other glomerular diseases were diagnosed by renal biopsy.

\section{The Effect of Amiloride and Triamterene on Proteinuria}

At week 0 , the baseline mean 24 -h urine protein was $2.90 \pm 1.67 \mathrm{~g}$, UPCR was $2.76 \pm 1.75 \mathrm{~g} / \mathrm{g}$, and UACR was $2.25 \pm 1.42 \mathrm{~g} / \mathrm{g}$. Except 2 patients (patients no. 2 and 7), all patients that received amiloride demonstrated a reduction of 24-h urine protein excretion. Surprisingly all patients that received triamterene had a reduction in 24-h urine protein excretion as well (Fig. 3). We measured 24-h urine creatinine to monitor the accuracy of sample collection. We noticed that the preamiloride 24 -h urine collection in patient no. 7 was likely undercollected as his 24 -h urine creatinine of that specimen was only $53.1 \%$ of the postamiloride 24 -h urine creatinine. In addition, his preamiloride 24 -h urine protein was only $53.5 \%$ of his UPCR value. So the values of $24 \mathrm{~h}$ urine excretion preand postamiloride treatment in patient no. 7 were discarded for the analysis. Overall, both amiloride and triamterene reduced 24 -h urine protein significantly (Ta- 
Table 2. The effect of amiloride and triamterene on proteinuria

\begin{tabular}{lllll}
\hline & Amiloride pre and post & $p$ value & Triamterene pre and post & $p$ value \\
\hline 24-h urine protein, g & $3.02 \pm 1.79$ and $1.85 \pm 1.09$ & 0.002 & $3.02 \pm 1.51$ and $2.03 \pm 1.52$ & 0.02 \\
UPCR, g/g & $2.77 \pm 1.91$ and $1.89 \pm 1.67$ & 0.01 & $2.85 \pm 1.91$ and $2.01 \pm 1.69$ & 0.01 \\
UACR, g/g & $2.25 \pm 1.54$ and $1.36 \pm 1.00$ & 0.005 & $2.21 \pm 1.45$ and $1.58 \pm 1.23$ & 0.03 \\
\hline
\end{tabular}

UPCR, urine protein to creatinine ratio; UACR, urine albumin to creatinine ratio.

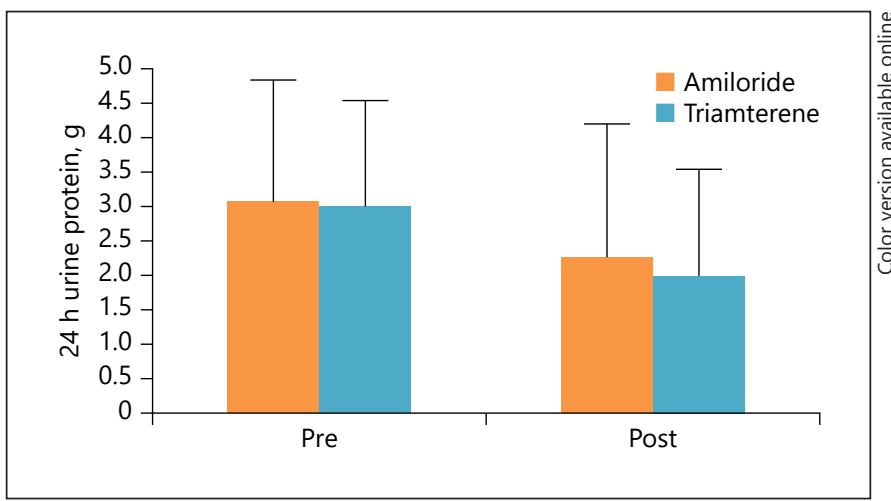

Fig. 4. The comparison of 24 -h urine protein excretion between amiloride and triamterene before and after the treatment. There was no significant difference in the urine protein excretion between the two groups, either pre $(p=0.85)$ or post-treatment $(p=$ $0.45)$.

ble 2). Amiloride decreased 24 -h urine protein by $38.7 \%$ $(p=0.002)$, while triamterene reduced proteinuria by $32.8 \%(p=0.02)$. When we compared UPCR and UACR pre- and posttreatment, amiloride lowered UPCR by $31.8 \%(p=0.01)$, UACR by $39.6 \%(p=0.005)$, while triamterene lowered UPCR by $29.5 \%(p=0.01)$, UACR by $28.5 \%(p=0.03)$. There was no significant difference between amiloride and triamterene in reducing $24-\mathrm{h}$ urine protein ( $p=0.45$, Fig. 4 ).

When the 24-h urine protein excretion at the end of the entire trial was compared with the baseline levels in each individual patient regardless of the order of the trial drugs they received, every patient had a reduction in 24-h urine protein. The degree of reduction varied from 3.1 to $68.4 \%$ with an average of $39.7 \%$ (Fig. 3 ).

Every patient went through a 4 -week washout period before crossing over to the other drug to eliminate carryover effects. We found that 24-h urine protein at week 12 (postwashout) increased compared to that measured at week 8 (prewashout) in both groups (amiloride: prewashout $2.22 \pm 0.80 \mathrm{~g}$ vs. postwashout $3.27 \pm 0.78 \mathrm{~g}$; triam- terene: prewashout $2.00 \pm 4.03$ g vs. postwashout $2.98 \pm$ 5.26 g; Fig. 3), suggesting the carryover effects from the previous treatment were minimized during the washout period.

\section{Changes in BP and Body Weight}

Amiloride significantly decreased systolic BP by 12.3 mm Hg $(p=0.04)$ but did not significantly decreased diastolic BP $(p=0.09)$. Triamterene did not change systolic or diastolic BP $(p=0.76, p=0.09$, respectively, Table 3$)$.

Neither amiloride nor triamterene changed patients' body weight significantly $(p=0.40, p=0.34$, respectively, Table 3).

\section{Changes in eGFR and Sk}

Three patients exited the study after 1-2 weeks due to hyperkalemia. Among the 12 patients who completed the trial, amiloride significantly increased the Sk concentration $(p=0.03)$, as did triamterene $(p=0.03$, Table 4$)$. Amiloride did not change eGFR significantly $(p=0.48)$, while triamterene significantly lowered eGFR $(p=0.007$, Table 4). Notably, the patients who experienced a reduction of eGFR on triamterene all improved eGFR after discontinuing the medication during the washout phase or after completion the trial.

\section{Discussion}

Proteinuria is an indicator of injury to the glomerular filtration barrier and has been a therapeutic target to manage CKD. Over the past 3 decades, RAAS blockade by ACE inhibitor or ARB has been the mainstay treatment to reduce proteinuria and hinder the progression of CKD. However, many patients with macroalbuminuria have residual albuminuria despite RAAS blockade, which is associated with worse renal outcome as is the baseline albuminuria [16]. Although dual RAAS blockade with $\mathrm{ACEI}$ and $\mathrm{ARB}$ can further reduce proteinuria, the combination therapy is associated with higher risk of acute 
Table 3. Changes in BP and body weight

\begin{tabular}{lcccc}
\hline & Amiloride pre and post & $p$ value & Triamterene pre and post & $p$ value \\
\hline Systolic BP, mm Hg & $137.4 \pm 21.1$ and $125.2 \pm 19.3$ & 0.04 & $138.1 \pm 19.9$ and $139.8 \pm 23.1$ & 0.76 \\
Diastolic BP, mm Hg & $77.6 \pm 6.8$ and $72.5 \pm 8.2$ & 0.09 & $76.5 \pm 12.7$ and $81.6 \pm 9.8$ & 0.09 \\
Body weight, $\mathrm{kg}$ & $83.7 \pm 22.4$ and $83.1 \pm 22.0$ & 0.40 & $83.9 \pm 21.2$ and $83.2 \pm 21.8$ & 0.34 \\
\hline
\end{tabular}

$\mathrm{BP}$, blood pressure.

Table 4. Changes in Sk and eGFR

\begin{tabular}{lcccc}
\hline & Amiloride pre and post & $p$ value & Triamterene pre and post & $p$ value \\
\hline $\mathrm{Sk}, \mathrm{mEq} / \mathrm{L}$ & $4.1 \pm 0.5$ and $4.40 \pm 0.43$ & 0.03 & $4.0 \pm 0.3$ and $4.3 \pm 0.4$ & 0.03 \\
$\mathrm{eGFR}, \mathrm{mL} / \mathrm{min} / 1.73 \mathrm{~m}^{2}$ & $79.5 \pm 24.3$ and $77.5 \pm 25.6$ & 0.48 & $80.8 \pm 23.2$ and $71.8 \pm 26.5$ & 0.007 \\
\hline
\end{tabular}

Sk, serum potassium; eGFR, estimated glomerular filtration rate.

kidney injury, hypotension, and hyperkalemia without benefits in reducing mortality [17]. Hence, identifying additional antiproteinuric agents has been imperative.

To our knowledge, this trial is the first clinical study specifically designed to investigate if $\mathrm{ENaC}$ inhibitor amiloride decreases proteinuria in patients with various proteinuric kidney diseases. We found that amiloride significantly decreased 24-h urine protein excretion in the patients who had received ACEI or ARB at the highest tolerable dose for at least 8 weeks prior to the study. Therefore, amiloride successfully reduced the "residual" proteinuria and the effect was additive to RAAS blockade.

Our study showed a higher degree of albuminuria reduction by amiloride (40\%) compared to another study that amiloride only reduced albuminuria by $10-15 \%$. In Unruh et al.'s [15] study, patients recruited to the trial had a lower degree of baseline proteinuria (mean UACR 1,120 $\pm 780 \mathrm{mg} / \mathrm{g}$, UPCR $>100 \mathrm{mg} / \mathrm{g}$ was needed for enrollment) than our patients (mean UACR 2,250 $\pm 1,420$ $\mathrm{mg} / \mathrm{g}$, UPCR $>1,000 \mathrm{mg} / \mathrm{g}$ was needed for enrollment). We think that the significant difference in baseline proteinuria between our study and Unruh et al.'s [15] study probably contributed to the difference in antiproteinuric effect of amiloride between the 2 studies.

Only amiloride but not its $\mathrm{ENaC}$ inhibitor analog - triamterene - was reported in animal studies and human case reports to reduce proteinuria, and to improve glomerulosclerosis $[11-15,18]$, we designed this crossover study which intended to use triamterene as a control drug. Surprisingly, our results show that triamterene re- duced proteinuria similarly to amiloride. The effect of triamterene in proteinuria reduction has not been reported previously.

It is not entirely clear how amiloride and triamterene attenuate proteinuria. In the process of proteinuria formation, a disruption of the glomerular filtration barrier is the common pathway shared by different glomerular disease. Damage to podocyte, a cellular structure that stabilizes glomerular filtration barrier and maintains its integrity, can lead to increased cell motility and effacement of foot processes which play a central role in glomerular filtration barrier dysfunction $[19,20]$. uPAR is a transmembrane protein that mediates cell motility, inflammation, tumor invasion and metastasis $[21,22]$. There is ongoing research to examine if UPAR is involved in the pathogenesis of proteinuric kidney disease $[23,24]$. Increased expression of UPAR mRNA and protein in podocytes was detected in several proteinuric animal models and human glomerular disease, suggesting upregulated uPAR levels in podocytes might contribute to enhanced podocyte migration, foot process effacement, and eventually proteinuria formation [25-29]. Amiloride, a potassi$\mathrm{um}$-sparing diuretic via its inhibition on $\mathrm{ENaC}$, has been shown to suppress uPAR expression in podocytes, reduce podocyte cell motility, decrease proteinuria, and attenuate glomerulosclerosis in proteinuric animal models $[9$, 18]. These data suggest that amiloride might be a potential antiproteinuric agent via suppressing uPAR expression in podocytes and maintaining a stable function of the glomerular filtration barrier. Our study in human glo- 
merular disease suggests that amiloride attenuates proteinuria in proteinuric kidney disease, which is consistent with the results from animal studies.

Interestingly, we found that triamterene was as effective as amiloride in reducing proteinuria. Our results contrast with the report that amiloride but not triamterene reduced proteinuria and ameliorated glomerulosclerosis in the proteinuric animal models [9]. The reason for the difference is not clear but could entail species alteration in $\mathrm{ENaC}$ inhibition by triamterene. So far neither human studies nor other animal studies have reported if triamterene reduces proteinuria. Triamterene has not been reported if it is related to UPAR expression as well.

Amiloride and triamterene are traditionally considered as relatively modest diuretics through inhibition of $\mathrm{ENaC}$ in collecting ducts. However, recent research suggests that $\mathrm{ENaC}$ inhibitors can be used to treat resistant edema and hypertension in patients with nephrotic syndrome. Emerging data have shown that overactivated $\mathrm{ENaC}$ due to aberrantly filtered plasminogen and renal conversion to plasmin - an enzyme proteolyzing and activating $\mathrm{ENaC}$ - plays an important role in volume overload in nephrotic syndrome [30,31]. Both amiloride and triamterene have been reported to successfully treat refractory edema in patients with nephrotic glomerular disease [32-34]. Amiloride improved BP in African Americans who were resistant to conventional antihypertensive medications [35] and was as effective as mineralocorticoid receptor spironolactone to treat patients with resistant hypertension [36]. The patients enrolled in our study were all receiving ACEI or ARB and had relatively wellcontrolled BP. Our study showed amiloride decreased systolic BP significantly by $12.3 \mathrm{~mm} \mathrm{Hg}$, although that was not seen with triamterene. Neither drugs reduced body weight significantly. The majority of the patients enrolled in our study had nonnephrotic-range proteinuria without either resistant hypertension or edema. This might explain that the effects of amiloride and triamterene in decreasing BP and body weight was not prominent in our study since $\mathrm{ENaC}$ was not overwhelmingly activated as it is under the nephrotic condition. Since our patients' BP control was already relatively optimized before the treatment and triamterene improved proteinuria without affecting BP, we think that the effect of proteinuria reduction by these 2 trial drugs is likely independent of $\mathrm{BP}$ reduction.

Three out of 20 patients (15\%) developed hyperkalemia 1 week after starting the medication and had to be withdrawn from the trial. Both medications increased $\mathrm{Sk}$ concentration by an average of $0.3 \mathrm{mmol} / \mathrm{L}$. Triamterene

Amiloride Reduces Proteinuria in

Chronic Kidney Disease lowered eGFR, but this side effect was reversible. It was only seen when patients were on the medication and resolved after discontinuing the drug during the washout phase and after the trial was completed. Overall both medications were well tolerated, but Sk concentration needed to be monitored 1-2 weeks after the medications were started.

Our study has several limitations. First, this is a pilot study that only recruited a small number of patients. Our results could have been skewed by the sample size. Second, we only selected the patients with Sk below 4.5 $\mathrm{mEq} / \mathrm{L}$ or $4.8 \mathrm{mEq} / \mathrm{L}$ based on their baseline renal function to avoid hyperkalemia, and majority of our patients had mild CKD. We did not test the safety in the patients with more advanced CKD (CKD stage IIIB or above). Third, we only tested the antiproteinuric effect of each drug for 8 weeks. It is unknown if amiloride and triamterene can provide long-term effect in proteinuria reduction, and if the drugs can hinder the progression of CKD. Forth, we only measured 24-h urine protein, UPCR, and UACR once at each time point. We might have obtained more accurate data and minimized the variation of sample collection if we had 2 urine sample collections at each time point.

Although RAAS blockade has been an effective antiproteinuric treatment to improve patient's renal outcomes, proteinuria is still not completely resolved in many patients. The degree of residual proteinuria is proportionally associated with renal risk as that of baseline proteinuria [16]. The search for antiproteinuric agents has been ongoing for many years. While mineralocorticoid receptor antagonists have shown some favorable results in renoprotection, the side effect of antiandrogen in spironolactone such as gynecomastia has kept many male patients from using it. Our study in the patients with a variety of proteinuric kidney diseases along with a few case reports by other groups [11-15] and animal studies [9] suggests that amiloride and triamterene could provide additional antiproteinuric effect after RAAS blockade. Both medications have been on market for decades with well-tolerated safety profile and low costs. Recent studies have indicated that amiloride inhibits both uPAR $[9,18]$ and UPA [37] which are 2 contributors in the pathogenesis of nephrotic syndrome. While uPAR probably is involved in podocyte dysfunction and proteinuria formation [26-29], uPA plays a role in $\mathrm{ENaC}$ overactivation and edema formation under nephrotic conditions [30, 31]. Therefore, as a medication blocking 2 pivotal mediators - uPAR and uPA - that are involved in the pathogenesis of proteinuric kidney disease, amiloride and probably 
triamterene could serve as unique agents to treat proteinuria, edema, and hypertension in these patients. Because this is a pilot study with a small sample size and hyperkalemia was not uncommon in this study, we do not suggest to use amiloride or triamterene to treat proteinuria in the clinical practice yet. But we think given the profiling of these 2 agents and our pilot study results, more clinical studies are needed to further investigate their effects on proteinuria reduction and renoprotection.

\section{Acknowledgements}

We would like to thank Dr. Michael Choi and Dr. Michael Lipkowitz for reviewing this article and providing valuable comments. This clinical trial was sponsored by a grant from the Center for Hypertension, Kidney, and Vascular Research at Georgetown University Medical Center. This study is publicized at clinicaltrials.gov NCT02522650.

\section{Statement of Ethics}

The study was conducted at the Clinical Research Unit of Georgetown-Howard Universities Center for Clinical and Translational Science (GHUCCTS). It was approved by Georgetown University Medical Center Institutional Review Board and is publicized at clinicaltrials.gov NCT02522650. All the patients gave written informed consents to the study.

\section{Conflict of Interest Statement}

All the authors declared no conflict of interests related to this clinical trial.

\section{Author Contributions}

W. Shen was involved in study design, patient visits, data collection \& analysis, drafting and revising the manuscript. M. Alshehri was involved in data collection and analysis. S. Desale was involved in statistical analysis and data interpretation. C. Wilcox was involved in study design, data interpretation, and revising the manuscript.

\section{References}

1 Hemmelgarn BR, Manns BJ, Lloyd A, James MT, Klarenbach S, Quinn RR, et al. Relation between kidney function, proteinuria, and adverse outcomes. JAMA. 2010;303(5):4239.

2 Berhane AM, Weil EJ, Knowler WC, Nelson RG, Hanson RL. Albuminuria and estimated glomerular filtration rate as predictors of diabetic end-stage renal disease and death. Clin J Am Soc Nephrol. 2011;6(10):2444-51.

3 Bim H, Christensen E. Renal albumin absorption in physiology and pathology. Kidney Int. 2006;69:440-9.

4 Group TG. Randomised placebo-controlled trial of effect of ramipril on decline in glomerular filtration rate and risk of terminal renal failure in proteinuric, non-diabetic nephropathy. The GISEN Group (Gruppo Italiano di Studi Epidemiologici in Nefrologia). Lancet. 1997;349(9069):1857-63.

5 Lewis EJ, Hunsicker LG, Bain RP, Rohde RD. The effect of angiotensin-converting-enzyme inhibition on diabetic nephropathy. The Collaborative Study Group. N Engl J Med. 1993; 329(20):1456-62.

6 Perkovic V, Jardine MJ, Neal B, Bompoint S, Heerspink HJL, Charytan DM, et al. Canagliflozin and renal outcomes in type 2 diabetes and nephropathy. N Engl J Med. 2019; 380(24):2295-306

7 Bakris GL, Agarwal R, Anker SD, Pitt B, Ruilope LM, Rossing P, et al. Effect of finerenone on chronic kidney disease outcomes in type 2 diabetes. N Engl J Med. 2020;383(23): 2219-29.
8 Sepehrdad R, Chander PN, Oruene A, Rosenfeld L, Levine S, Stier CT. Amiloride reduces stroke and renalinjury in stroke-prone hypertensive rats. Am J Hypertens. 2003;16(4):312-8.

9 Zhang B, Xie S, Shi W, Yang Y. Amiloride offtarget effect inhibits podocyte urokinase receptor expression and reduces proteinuria. Nephrol Dial Transplant. 2012;27(5):1746-55.

10 Deegens JK, Wetzels JF. Glomerular disease: the search goes on: suPAR is not the elusive FSGS factor. Nat Rev Nephrol. 2014;10(8): 431-2.

11 Trimarchi H, Forrester M, Lombi F, Pomeranz V, Raña MS, Karl A, et al. Amiloride as an alternate adjuvant antiproteinuric agent in Fabry disease: the potential roles of plasmin and uPAR. Case Rep Nephrol. 2014;2014: 854521.

12 Trimarchi H, Canzonieri R, Muryan A, Schiel A, Araoz A, Paulero M, et al. Podocyturia: a clue for the rational use of amiloride in Alport renal disease. Case Rep Nephrol. 2016;2016: 1492743.

13 Trimarchi H, Paulero M, Canzonieri R, Schiel A, Iotti A, Costales-Collaguazo $\mathrm{C}$, et al. In acute IgA nephropathy, proteinuria and creatinine are in the spot, but podocyturia operates in silence: any place for amiloride? Case Rep Nephrol. 2017;2017:1292531.

14 Anderson H, Hansen PBL, Bistrup C, Nielsen F, Henriksen JE, Jensen BL. Significant natriuretic and antihypertensive action of the epithelial sodium channel blocer amiloride in diabetic patients with and without nephropathy. J Hypertens. 2016;34:1621-9.
15 Unruh ML, Pankratz VS, Demko JE, Ray EC Hughey RP, Kleyman TR. Trial of amiloride in type 2 diabetes with proteinuria. Kidney Int Rep. 2017;2(5):893-904.

16 de Zeeuw D, Remuzzi G, Parving HH, Keane WF, Zhang Z, Shahinfar S, et al. Proteinuria, a target for renoprotection in patients with type 2 diabetic nephropathy: lessons from RENAAL. Kidney Int. 2004; 65(6):2309-20.

17 Fried LF, Emanuele N, Zhang JH, Brophy M, Conner TA, Duckworth W, et al. Combined angiotensin inhibition for the treatment of diabetic nephropathy. N Engl J Med. 2013; 369(20):1892-903.

$18 \mathrm{Xu} \mathrm{LB}$, Chi N, Shi W. Amiloride, a urokinasetype plasminogen activator receptor (uTPA) inhibitor, reduces proteinuria in podocytes. Genet Mol Res. 2015;14:9518-29.

19 Mathieson PW. Proteinuria and immunity: an overstated relationship? N Engl J Med. 2008;359(23):2492-4.

20 Tryggvason K, Patrakka J, Wartiovaara J. Hereditary proteinuria syndromes and mechanisms of proteinuria. N Engl J Med. 2006; 354(13):1387-401.

21 Madsen CD, Ferraris GM, Andolfo A, Cunningham $\mathrm{O}$, Sidenius N. uPAR-induced cell adhesion and migration: vitronectin provides the key. J Cell Biol. 2007;177(5):927-39.

22 Wei Y, Waltz DA, Rao N, Drummond RJ, Rosenberg S, Chapman HA. Identification of the urokinase receptor as an adhesion receptor for vitronectin. J Biol Chem. 1994;269(51): 32380-8. 
23 Svenningsen P, Hinrichs GR, Zachar R, Ydegaard R, Jensen BL. Physiology and pathophysiology of the plasminogen system in the kidney. Pflugers Arch. 2017;469:141523.

24 Raij L, Tian R, Wong JS, He JC, Campbell KN. Podocyte injury: the role of proteinuria, urinary plasminogen, and oxidative stress. Am J Physiol Renal Physiol. 2016;311(6):F130817.

25 Dande RR, Peev V, Altintas MM, Reiser J. Soluble urokinase receptor and the kidney response in diabetes mellitus. J Diabetes Res. 2017;2017:3232848.

26 Wei C, El Hindi S, Li J, Fornoni A, Goes N, Sageshima J, et al. Circulating urokinase receptor as a cause of focal segmental glomerulosclerosis. Nat Med. 2011;17(8):952-60.

27 Yu H, Suleiman H, Kim AH, Miner JH, Dani A, Shaw AS, et al. Rac1 activation in podocytes induces rapid foot process effacement and proteinuria. Mol Cell Biol. 2013;33(23): 4755-64.
28 Trimarchi H, Canzonieri R, Schiel A, Costales-Collaguazo C, Stern A, Paulero M, et al. In IgA nephropathy, glomerulosclerosis is associated with increased urinary CD80 excretion and urokinase-type plasminogen activator receptor-positive podocyturia. Nephron Extra. 2017 May-Aug;7(2):52-61.

29 Monte MD, Cammalleri M, Pecci V, Carmosino M, Procino G, Pini A, et al. Inhibiting the urokinase-type plasminogen activator receptor system recovers STZ-induced diabetic nephropathy. J Cell Mol Med. 2019;23:1034-49.

30 Hinrichs GR, Weyer K, Friis UG, Svenningsen P, Lund IK, Nielsen R, et al. Urokinasetype plasminogen activator contributes to amiloride-sensitive sodium retention in nephrotic range glomerular proteinuria in mice. Acta Physiol. 2019;227(4):e13362.

31 Passero CJ, Mueller GM, Rondon-Berrios H, Tofovic SP, Hughey RP, Kleyman TR. Plasmin activates epithelial $\mathrm{Na}+$ channels by cleaving the gamma subunit. J Biol Chem. 2008;283(52):36586-91.

32 Hinrichs GR, Mortensen LA, Jensen BL, Bistrup C. Amiloride resolves resistant edema and hypertension in a patient with nephrotic syndrome: a case report. Physiol Rep. 2018;6: e13743.
33 Hoorn EJ, Ellison DH. Diuretic resistance. Am J Kidney Dis. 2017;69(1):136-42.

34 Yamaguchi E, Yoshikawa K, Nakaya I, Kato K, Miyasato Y, Nakagawa T, et al. Liddle'slike syndrome associated with nephrotic syndrome secondary to membranous nephropathy: the first case report. BMC Nephrol. 2018; 19:122-6.

35 Saha C, Eckert GJ, Ambrosius WT, Chun TY, Wagner MA, Zhao Q, et al. Improvement in blood pressure with inhibition of the epithelial sodium channel in blacks with hypertension. Hypertension. 2005;46(3):481-7.

36 Williams B, MacDonald TM, Morant SV, Webb DJ, Sever P, McInnes GT, et al. Endocrine and haemodynamic changes in resistant hypertension, and blood pressure responses to spironolactone or amiloride: the PATHWAY-2 mechanisms substudies. Lancet Diabetes Endocrinol. 2018;6(6):464-75.

37 Vassalli JD, Belin D. Amiloride selectively inhibits the urokinase-type plasminogen activator. FEBS Lett. 1987;214(1):187-91. 